\title{
25
}

\section{Determining Peak Flow Recurrence in Combined Basins with Limited Flow Data using Genetic Algorithm Calibration}

\author{
Hazem Gheith, Mary Carmichael, Gregory Barden, and
} M. P. Cherian

The City of Columbus, Ohio, completed a comprehensive Wet Weather Management Plan (WWMP) to mitigate hydraulic deficiencies in the City's main trunk sewers and to perform a Long Term Control Plan (LTCP) to address combined sewer overflows (CSO) to the Scioto and Olentangy Rivers. The recommended solution includes a deep tunnel that will capture combined sewage overflows from the downtown CSO regulators. This combined flow tunnel will ensure that peak flow from the downtown combined sewer basins is captured up to a specific peak flow recurrence level. Due to the lack of long-term flow meter and downtown rainfall data, it was difficult to estimate peak flows for selected recurrence levels. Therefore, the design team proposed a procedure where available two to three-years of quality-checked flow meter data and concurrent 15-min rain gauge data between the years 2000 and 2003 was used to calibrate a SWMM model using the PCSWMM Genetic Algorithm Calibration (GAC). The long-term hourly rainfall data, collected by the National Weather Service at Port Columbus International Airport, in conjunction with the calibrated SWMM $4.4 \mathrm{~h}$ model was then used to generate $56 \mathrm{y}$ of flow records from each combined basin.

Gheith, H., M. Carmichael, G. Barden and M.P. Cherian. 2008. "Determining Peak Flow Recurrence in Combined Basins with Limited Flow Data Using Genetic Algorithm Calibration." Journal of Water Management Modeling R228-25. doi: 10.14796/JWMM.R228-25.

(C) CHI 2008 www.chijournal.org ISSN: 2292-6062 (Formerly in Reliable Modeling of Urban Water Systems. ISBN: 978-0-9808853-0-9) 
This chapter details how we applied the GAC procedure to calibrate the SWMM Runoff module parameters for each combined sewer basin in downtown Columbus. Calibration was performed on the largest 10 to 12 storm events recorded between the years 2000 and 2003. These storm events covered a wide-range of short, medium, and long durations with high rainfall intensities. Runoff parameters were controlled within suitable uncertainty ranges. The GAC was applied until the peak flow values of most of the highintensity calibrated storms were within $\pm 10 \%$ of the observed peak flow values. The hourly rainfall data from Port Columbus International Airport was then used with the calibrated Runoff modules to predict the highest peak flows that occurred over the 56-y recorded rain period. The Cunnane plotting position formula was then applied to the predicted peak flow data to generate a flow recurrence curve. The predicted peak flow recurrence was corrected to account for the difference between using the 1-h. time step rain data from Port Columbus International Airport versus the 15-min. time step rain data from the downtown rain gauges that were used during the GAC process. The proposed procedure allowed for a reasonable prediction of the 1-, 2-, 5-, and 10-y recurrence peak combined flow while overcoming the lack of adequate long-term flow data.

\subsection{Background}

The City of Columbus, Division of Sewerage and Drainage (DOSD) serves the wastewater needs of Franklin County and portions of the surrounding counties in Central Ohio. The population of the serviced area (year 2000) is about $1,072,000$ based on the 2000 Census data. The serviced area encompasses approximately 130,000 acres $(52,845$ ha), of which approximately 8,200 acres $(3,333 \mathrm{ha})$ are combined sewers. The collection system is serviced by two treatment plants, Jackson Pike Waste Water Treatment Plant (JPWWTP) and Southerly Waste Water Treatment Plant (SWWTP).

The combined sewer system is located in the central downtown portion of the City of Columbus as shown in Figure 25.1. Combined sewage mainly discharges into the Olentangy Scioto Interceptor Sewer (OSIS). During Wet Weather Flow (WWF) conditions, CSO regulators are designed to discharge excess combined flow directly to the Olentangy and/or Scioto Rivers. Wet weather flow can also be diverted into the Whittier Street Storm Stand-By Tanks (WSST). These tanks provide both storage and primary treatment for overflows that discharge to the Scioto River. 


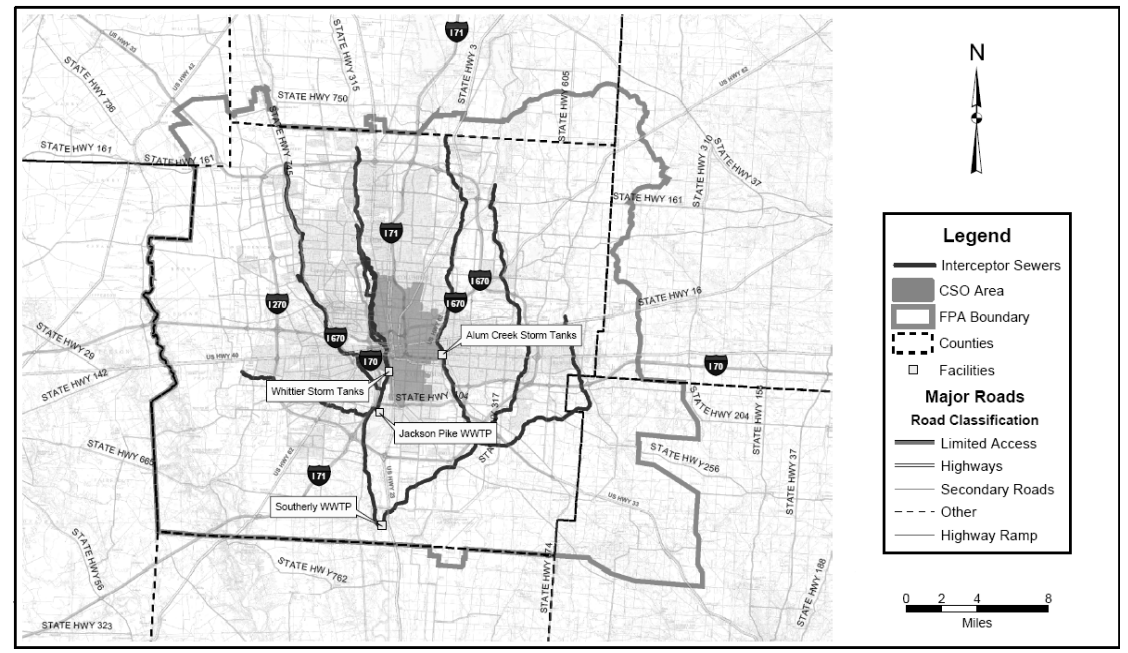

Figure 25.1 City of Columbus Facility Planning Area (FPA) Boundary Combined Area of the City of Columbus is located in the Central area of the FPA

There are currently 30 permitted CSO locations in the Columbus combined sewer system, of which 29 CSOs are tributary to the Scioto and Olentangy Rivers. The OSIS is the only contributor to the WSST. The WSST consists of three tanks with a total capacity of 4.1 million gallons (MG). The WSST were designed to provide a rated capacity of 204 million gallons per day $(10,500 \mathrm{~L} / \mathrm{s})$ with a 30-min. detention time when full (Gregory et al, 1933). In a typical year, the largest volume of combined sewage overflow occurs at the WSST facility.

The City of Columbus entered into a Consent Order (CO) with the State of Ohio pertaining to the CSOs which emanate from the combined sewage portion of the collection system during wet weather events. The CO was filed on September 17, 2004. This CO required the City to submit an LTCP in compliance with the requirements of the U.S. EPA CSO Control Policy which was issued in 1994. The LTCP was also required to be submitted to the Ohio EPA by July 1, 2005 (City of Columbus DOSD, 2005). The primary goal of the LTCP was to bring all CSO discharges into compliance with the technology-based and water-quality based requirements.

The $\mathrm{CO}$ sets forth criteria that must be included in the evaluation of interim solutions, and requires that, at a minimum, the City shall achieve a substantial reduction in CSO no later than July 1, 2010. The City's interim 
LTCP proposes to build the first phase of the OSIS Augmentation and Relief Sewer (OARS), which will extend from WSST to the JPWWTP. The OARS Phase I, along with short term improvements at the treatment plants, (especially at JPWWTP), will allow the City to significantly reduce CSOs.

The proposed OARS was originally designed to be a near surface large box-shaped conduit measuring $12 \mathrm{ft} \times 16 \mathrm{ft},(3.7 \mathrm{~m} \mathrm{x} 4.9 \mathrm{~m})$ and receive CSO discharges from each combined basin. Flow would be conveyed through the OARS to the JPWWTP for secondary treatment, CSO high rate treatment, or overflow to the Scioto River. When all phases of OARS (Phases II thru IV) are completed, it would allow a maximum of four overflows to occur in a typical year at a location near the JPWWTP.

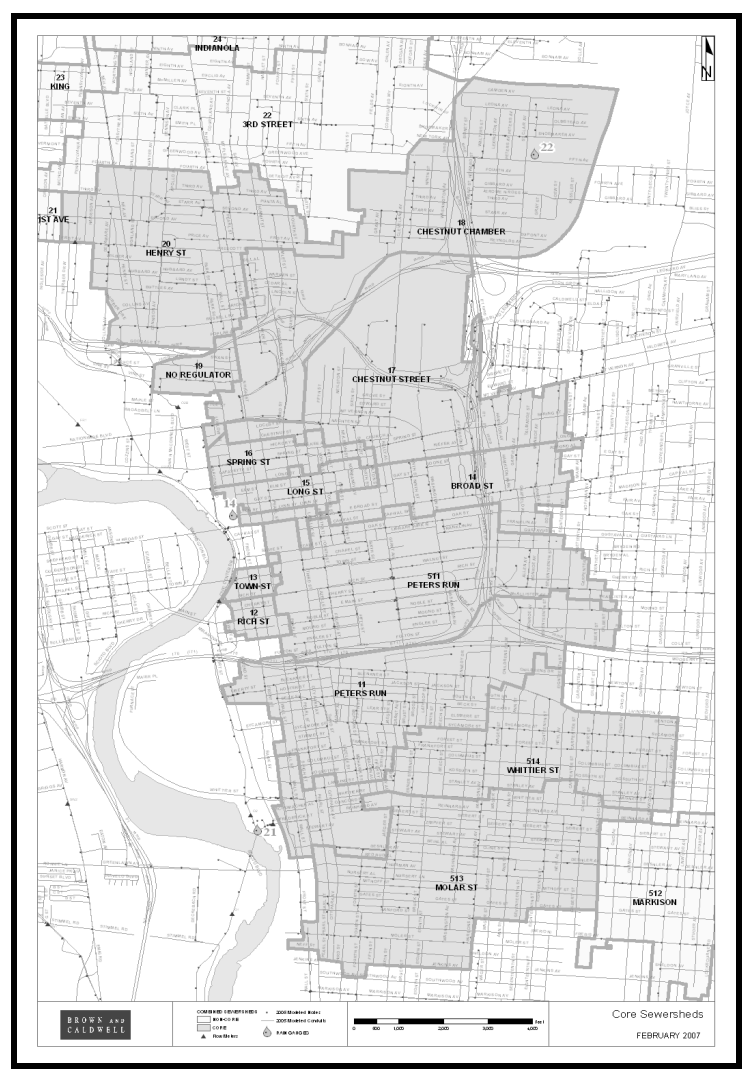

Figure 25.2 Combined basins in downtown Columbus. 
During the design phase, constructability and cost considerations dictated that the OARS should be constructed as a deep tunnel. As a result, not all CSOs would be intercepted into the OARS which directly affect the proposed mitigation of the $\mathrm{CSO}$ activation in the downtown regulators. Consequently the City of Columbus wanted assurance that the OARS project provided a level of service for the downtown combined system (see Figure 25.2) that was higher than the typical year.

Therefore, the City requested further evaluation to ensure that peak flows from these combined basins are captured up to a higher recurrence level such as the 2-, 5-, and 10-y recurrence level. The exact level of control would be selected based on a cost effectiveness evaluation.

Analysis to determine the appropriate level of service was hindered by lack of adequate flow records from combined basins. In this chapter, a methodology is presented to determine the 2-, 5-, and 10-y peak flow recurrence values from combined basins in the downtown area of the City of Columbus utilizing limited flow records. Available flow data collected by the City at each of the combined basins between the years 2000 and 2003 were utilized. The existing hydraulic models of each combined basin were calibrated to ten to twelve of the highest flow events that occurred during the metering period. Basins with limited or poor flow metering data were assigned runoff parameters similar to adjacent basins with same landuse distribution. Calibrated models were then run using 56 y of 1-h. rain gauge data from Port Columbus International Airport. Using the plotting position probability formula,

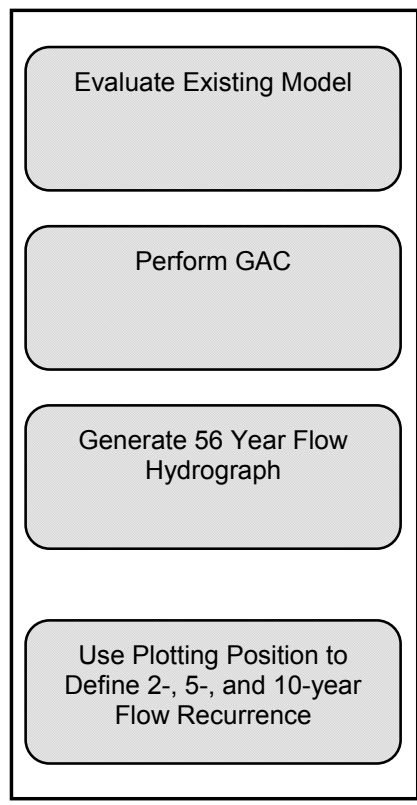

Figure 25.3 Flow recurrence development procedure. the peak flow data from each year was then used to determine the peak flow recurrence (2-, 5- and 10-y) values for each basin. The process is summarized in Figure 25.3. 


\subsection{Evaluation of Metered Data and Hydrology Model}

\subsubsection{General Description of the Study Basins}

There are twenty combined basins located within the downtown area that have CSO regulators. The regulators, arranged from upstream to down stream (North to South) are: Hudson Street, Doe Alley, Frambes Avenue, Indianola Avenue, King Avenue, Third Avenue, First Avenue, Henry Street, Chestnut Street, Spring Street, Long Street, Broad Street, Capital Street, State Street, Town Street, Rich Street, Peters Run, Whittier Street, Moler Street and Markison Avenue CSO regulators. Seven upstream CSO regulators (Hudson Street, Doe Alley, Frambes Avenue, Indianola Avenue, King Avenue, Third Avenue and First Avenue) discharge directly into the Olentangy River. They are located just upstream from City of Columbus downtown area. The rest of the CSO regulators located in the downtown area, discharge into the Scioto River.

Configuration of the discharges from the CSO regulators into the receiving waters varies. CSO from Henry Street regulator is intercepted by a long, approximately $6000 \mathrm{ft}(1829 \mathrm{~m})$, 96-in. (2440 mm) relief pipe extended through the downtown area to the Scioto River. The overflows from the Chestnut Street, Spring Street and Long Street regulators are intercepted into one long storm pipe $(\sim 4000 \mathrm{ft} / 1220 \mathrm{~mm})$ that discharges into the Scioto River. CSO activations from Broad Street, Town Street, Rich Street, Capital Street, State Street, Peters Run, Whittier Street and Moler Street regulators are conveyed directly to the Scioto River through short length pipes $(\sim 100-300 \mathrm{ft}$ or $31-92 \mathrm{~m})$. The Markison Avenue regulator overflow discharges into a storm pipe which collects large amount of additional storm flow from upstream and downstream storm basins before it discharges into the Scioto River, downstream of the downtown area. Therefore the Markison Avenue CSO does not directly contribute to the pollution problems in the downtown area.

Since the City of Columbus needed assurance that the new OARS design would provide high level of service at downtown regulators, in this evaluation, only the procedures utilized to develop the 2-, 5-, and 10-y peak flow recurrence values in the twelve downtown combined basins are presented. 


\subsubsection{Evaluate Observed Flow and Rain Data}

Flow Meter data

The City implemented a flow metering program for the combined basins beginning in 1999. Meter data was selected for analysis between the periods described in Table 25.1.

Table 25.1 Flow metering program for the combined basins.

\begin{tabular}{|c|c|c|c|c|}
\hline Meter ID & Regulator & CSO Discharge Location & Start Date & End Date \\
\hline \multirow[t]{19}{*}{ InputA } & Hudson St. & Upstream Downtown area & $11 / 7 / 200$ & $03 / 11 / 2003$ \\
\hline & Doe Alley & Upstream Downtown area & $11 / 06 / 1999$ & $11 / 28 / 2002$ \\
\hline & Frambes Ave & Upstream Downtown area & $12 / 31 / 1999$ & $03 / 26 / 2003$ \\
\hline & Indianola Ave & Upstream Downtown area & 08/18/1999 & $08 / 19 / 2004$ \\
\hline & King Ave & Upstream Downtown area & 02/16/1999 & $08 / 03 / 2002$ \\
\hline & Third Ave & Upstream Downtown area & $12 / 26 / 1999$ & $01 / 16 / 2003$ \\
\hline & First Ave & Upstream Downtown area & $10 / 01 / 1999$ & $07 / 01 / 2002$ \\
\hline & Henry St* & Downtown Columbus & $12 / 29 / 1999$ & $05 / 03 / 2003$ \\
\hline & Spring St* & Downtown Columbus & $10 / 03 / 2000$ & 03/19/2002 \\
\hline & Long $\mathrm{St}^{* \dagger}$ & Downtown Columbus & $01 / 01 / 2000$ & $27 / 6 / 201$ \\
\hline & Broad $\mathrm{St}^{* \dagger}$ & Downtown Columbus & $31 / 12 / 1999$ & $11 / 30 / 2002$ \\
\hline & Capital St & Downtown Columbus & \multicolumn{2}{|c|}{ No Flow Meter } \\
\hline & State St & Downtown Columbus & \multicolumn{2}{|c|}{ No Flow Meter } \\
\hline & Town ST* & Downtown Columbus & $12 / 31 / 1999$ & $09 / 25 / 2003$ \\
\hline & Rich st* & Downtown Columbus & $12 / 01 / 1999$ & $03 / 13 / 2002$ \\
\hline & Peters Run*广 & Downtown Columbus & $01 / 30 / 2000$ & $09 / 19 / 2001$ \\
\hline & Whittier st* & Downtown Columbus & $12 / 30 / 1999$ & $03 / 25 / 2002$ \\
\hline & Moler st* & Downtown Columbus & $12 / 31 / 1999$ & $07 / 16 / 2002$ \\
\hline & Markison Ave & $\begin{array}{c}\text { CSO discharges downstream } \\
\text { downtown area }\end{array}$ & $12 / 30 / 199$ & $07 / 04 / 2001$ \\
\hline \multirow[t]{6}{*}{ Input B } & Doe Alley & Upstream Downtown area & $12 / 31 / 1999$ & $08 / 14 / 2002$ \\
\hline & King Ave & Upstream Downtown area & $12 / 31 / 1999$ & $01 / 17 / 2003$ \\
\hline & First Ave & Upstream Downtown area & $12 / 31 / 1999$ & $08 / 13 / 2002$ \\
\hline & Chestnut St* & Downtown Columbus & $01 / 01 / 2000$ & $06 / 05 / 2002$ \\
\hline & Spring St* & Downtown Columbus & $12 / 31 / 1999$ & $04 / 04 / 2002$ \\
\hline & Whittier St* & Downtown Columbus & $12 / 31 / 1999$ & $05 / 01 / 2002$ \\
\hline
\end{tabular}

\footnotetext{
* Denotes CSO regulators considered in this chapter

${ }^{\dagger}$ Denotes basins with doubtful flow meter records
} 
All basins, except Capital Street and State Street, had flow meters that measured inflow to each CSO regulator. There were five combined basins that required two flow meters (described as Input A and Input B in Table 25.1), to measure all inflow to the CSO regulator. For calibration purposes, flow from Input A and Input B meters at these locations was combined into one total flow hydrograph. Chestnut Street basin had a flow meter with Input B ID.

The majority of flow meters provided adequate data for calibration. For those with insufficient data, problems were caused by erratic velocity, meter malfunctions and/or downstream flow impacts. Downstream flow impacts primarily occurred during high flow events when meters experienced backup and surcharging conditions. As a result, the peak flow was shaved since flow was stored in the upstream sewers. Backflow conditions hindered the ability to determine the true peak flows for these events. An example of the backflow effect is shown in Figure 25.4. Due to this backup effects and the uncertainty on how much of the peak flow was shaved, the recorded high peak flow is unusable for the hydrology calibration purposes.

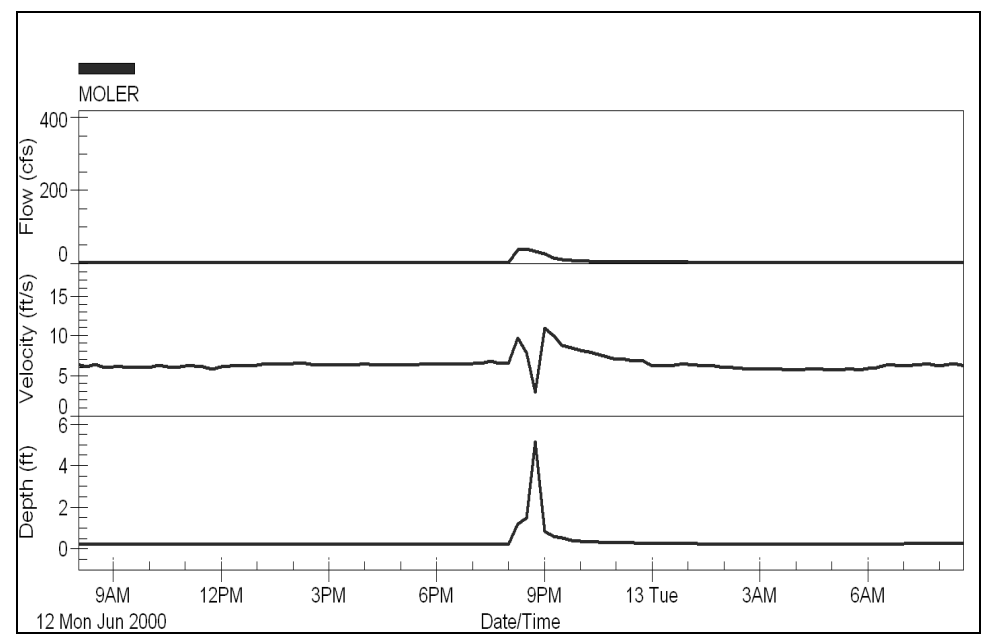

Figure 25.4 Example of backflow effect at Moler Street CSO regulator water surcharge conditions due to downstream backups reduced velocity and reduced peak flow.

Evaluation of flow meter data concluded that eight combined sewer basins had valid data for calibration purposes. These basins were Henry Street, Chestnut Street, Spring Street, Town Street, Rich Street, Whittier 
Street and Moler Street. Three combined sewer basins (Long Street, Broad Street, and Peters Run) had doubtful flow meter data for the entire metering period. In order to evaluate these basins using the 56 y of rain gauge data from the Columbus International Airport, calibrated parameters from an adjacent basin with similar land use and runoff characteristics were utilized. Parameters from the Whittier Street CSO Regulator basin were applied to the Peters Run CSO regulator basin. Spring Street CSO Regulator basin parameters were utilized in both Broad and Long Street CSO Regulator basins.

\section{Rain Gauges}

The City maintains a network of permanent tipping bucket rain gauges throughout their wastewater service area. City rain gauges record data in 5-min. increments. For the GAC evaluation of the downtown CSO regulators, rainfall data was taken from gauges 14, 18, 20, 22, 23 and 24. The rain gauge locations are illustrated in Figure 25.2. The rain distribution over each basin for each storm event was calculated using a weighted average from the six rain gauges using the inverse distance square weighted factor.

As the GAC process progressed, it was found for some storms that the rainfall values calculated and applied in some basins were incorrect. Further analysis of rain data revealed that raw rain data recorded at one or more rain gauges was inaccurate. The most common occurrences were abnormal spikes in the rain gauge data, gauge malfunction or a gauge reading zero rain.

Determining the difference between a malfunctioning gauge and a gauge correctly reporting no rain was difficult. In some instances, the difference was discerned by comparing data from the different rain gauges during the storm event. For example, if during an event one gauge reported a constant 0.01 (default setting) while nearby gauges recorded varying values, this would indicate a gauge malfunction. An example of a gauge malfunction is illustrated in Table 25.2. Rain gauges 14 and 23 reported varying rainfall values for this event, while rain gauge 22 reported a constant 0.01 reading (default reading).

If an evaluation of raw rain data is inconclusive in distinguishing between a malfunctioning gauge and a gauge correctly reporting no rain, then comparison of the peak flow recorded at the meter provided a way to determine the validity of rain data. 
Table 25.2 Rainfall data for downtown area rain gauges.

\begin{tabular}{cccccc}
\hline Date & Hour & Minute & \multicolumn{3}{c}{ Rainfall Value (in) } \\
\cline { 4 - 6 } & & & RG14 & RG23 & RG22 \\
\cline { 4 - 6 } $5 / 18 / 2001$ & 12 & 45 & 0.02 & 0.01 & 0.01 \\
$5 / 18 / 2001$ & 18 & 0 & 0.01 & 0.01 & 0.01 \\
$5 / 18 / 2001$ & 18 & 15 & 0.03 & 0.03 & 0.01 \\
$5 / 18 / 2001$ & 18 & 30 & 0.03 & 0.02 & 0.01 \\
$5 / 18 / 2001$ & 18 & 45 & 0.02 & 0.03 & 0.01 \\
$5 / 18 / 2001$ & 19 & 0 & 0.02 & 0.04 & 0.01 \\
$5 / 18 / 2001$ & 19 & 15 & 0.01 & 0.11 & 0.01 \\
$5 / 18 / 2001$ & 19 & 30 & 0.13 & 0.08 & 0.01 \\
$5 / 18 / 2001$ & 19 & 45 & 0.02 & 0.01 & 0.01 \\
\hline
\end{tabular}

\subsubsection{Evaluate Suitability of Existing Hydraulic Model}

The original hydrology model, created and calibrated during the WWMP modeling effort, was used in this analysis. The WWMP hydrology model was calibrated to observed rainfall/flow events during the month of August 2000. This month was deemed appropriate because of the number and range of wet-weather events recorded then by the City flow meters. As can be seen in Table 25.3, the return periods for these events at the downtown rain gauges ranged from small (less than 2-month) to large (1- to 2-y), providing a favorable range of calibration events for LTCP modeling purposes.

Table 25.3 Summary of wet-weather events during August 2000 calibration period.

\begin{tabular}{ccc}
\hline Event & \multicolumn{2}{c}{ Return Period for Event } \\
\cline { 2 - 3 } & $\begin{array}{c}\text { Average of All Rain } \\
\text { Gauges }\end{array}$ & $\begin{array}{c}\text { Range at Local } \\
\text { Gauges }\end{array}$ \\
\cline { 2 - 3 } August 7 & Less than 2-month & Less than 2-month \\
August 9 & Less than 2-month & Less than 2-month \\
August 17 & 4-month to 6-month & 1-year to 2-year \\
August 24 & Less than 2-month & 2-month to 1-year \\
August 27 & Less than 2-month & Less than 2-month \\
August 27 & Less than 2-month & 4-month \\
\hline
\end{tabular}


In order to reduce the run time for the models, due to the tight project schedule, the runoff sub-catchments in each combined basin was lumped together into one runoff catchment per basin. All original hydrology parameters were averaged (weighed by area) in order to provide a starting parameter value for the GAC process. For example, the width, percent impervious, pervious and impervious storages, slope and Green-Ampt infiltration parameters were averaged. A reference model run was made for each combined basin in order to determine the validity of the level of calibration. The model results were plotted against the flow meter results for the highest ten to twelve events. For example, the computed model results against the actual observed flow meter results for Rich Street and Moler Street CSO Regulators are shown in Figures 25.5 and 25.6.

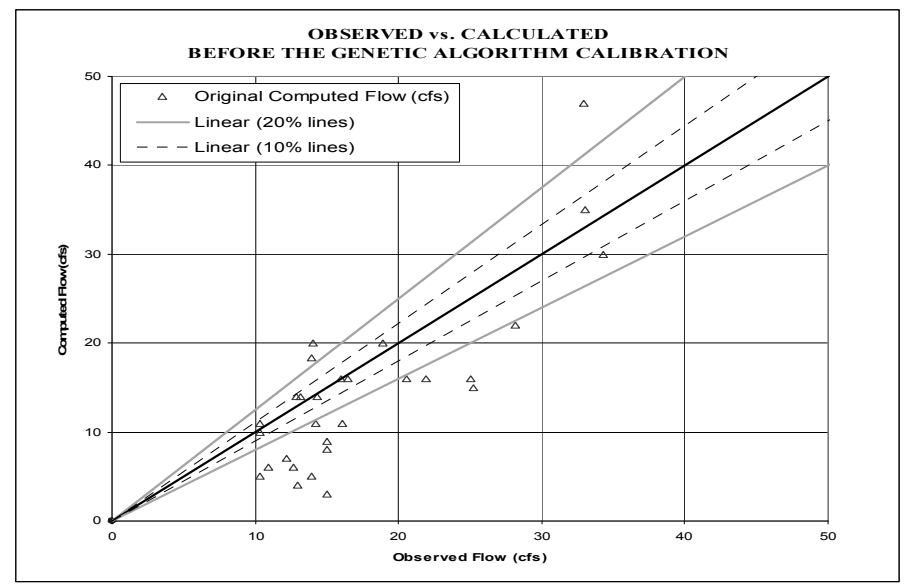

Figure 25.5 Observed vs. computed model results for Rich Street CSO Regulator before GAC.

Notice in the figures that the model might reasonably predict the peak flow associated with the medium to low level events, but is unable to predict the flows associated with the larger flow events with the same level of accuracy. The conclusion was that the 'original' models, which were calibrated to the events occurring only in August 2000 (maximum of 1-year storm), would not be accurate enough to predict the large flow events needed to develop the 2-, 5-, and 10-y peak flows. A hydrology model that was calibrated to higher storm levels was needed in order to out confidence on the predicted high return period peak flows. 


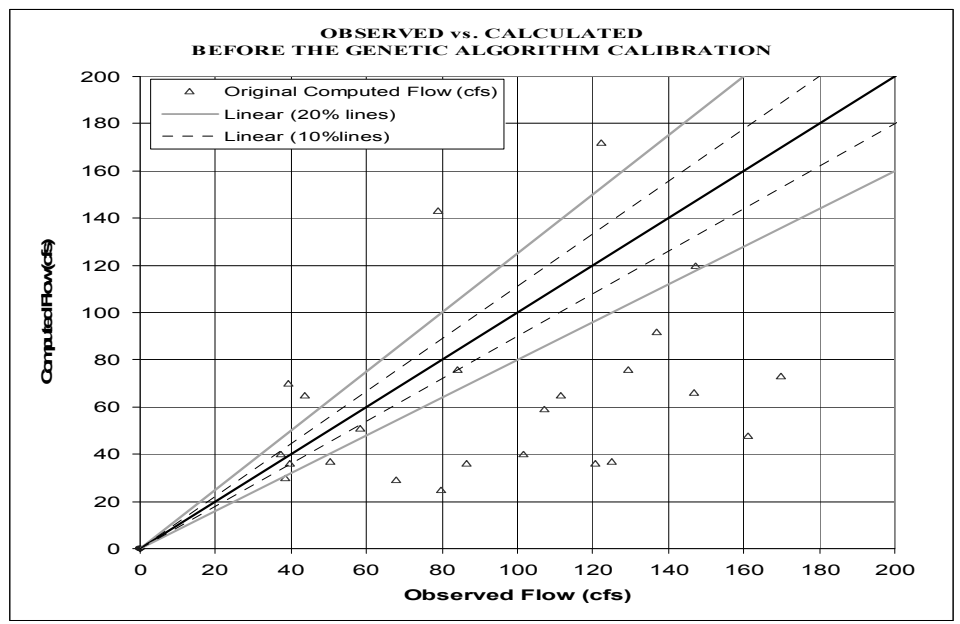

Figure 25.6 Observed vs. computed model results for Moler Street CSO Regulator before GAC.

\subsection{Genetic Algorithm Calibration Procedure}

\subsubsection{Setting up the GAC Modules}

The GAC process was used to update the parameters of the 'original' model in order to more accurately predict the peak flows generated during large storm events. The first step to setting up the GAC modules was to select the highest recorded peak flow events in each combined flow basin. During the evaluation of the flow meter data, the top 10 to 12 peak flow events were determined and reviewed for validity. The peak flow events recorded by the flow meters were compared to the rain gauge data. An event was deemed viable for calibration if the rain, velocity and depth data were deemed stable and found to be reasonable representative of the event. Separate PCSWMM modules were constructed for each storm event. After the events were selected and set-up in PCSWMM, the observed flow time series needed for the iterative GAC process were generated. A detailed outline of the GAC procedure is shown in Figure 25.7. 
Following the finalization of the GAC configuration, an acceptable uncertainty level was defined for each parameter. Defining the uncertainty level for each parameter is crucial to providing a valid calibrated model. The modeler must ensure that the calibrated parameters fall within acceptable boundaries. This step can be difficult because many parameters are interrelated (i.e. pervious and impervious storage, catchment width and percent impervious area).

For each basin, select the highest 10-12 peak events

Review \& correct rain data

distribution in each event

Generate observed flow

files for each selected event selected event

Define uncertainty range

for each parameter \& create a GAC file

Run GAC on the final selected events

Use GAC results an plo $45^{\circ}$ chart comparison

Figure 25.7 GAC Procedure 


\subsubsection{GAC Results}

Once the uncertainty level was defined for each runoff parameter, the GAC was performed. The GAC process may take numerous iterations before a model is deemed calibrated. The simple least squares (first dimensionless form) criterion for peak flow was used to identify the effectiveness of the calibration. The calibration was deemed acceptable when most of the highest calculated peak flows were within $\pm 20 \%$ of the observed peak flows for each event.

It was imperative to maintain a close eye on the change in the hydrology parameters to insure that they stay within acceptable limits. If the GAC results indicate a parameter that falls outside acceptable limits, additional research should be completed within that basin. If a hydrology parameter falls outside acceptable limits, this could be an indication that unknown hydrology conditions might have been overlooked.

As an example in this project, GAC activities to the Rich Street CSO regulator basin model required an increase in catchment area of more than $30 \%$. Under most circumstances, the catchment area parameter is expected to remain relatively unchanged (we only allowed maximum of $\pm 5 \%$ change in the basin area). In further research activities within the Rich Street CSO basin, we found a relief connection to the basin from the Town Street CSO regulator basin. The relief was inactive in small events (1-y or less) and, accordingly, it was not considered during the WWMP continuous typical year modeling effort. The GAC procedure also confirmed that this relief may be inactive for small events, but is active for the larger storm events. Figure 25.8 shows the location of the relief connection to Rich Street CSO regulator basin from Town Street CSO regulator basin.

During the GAC process, more emphasis was put on calibrating for the larger peak flow events. This was done to better prepare the model to predict acceptable responses during high storm events that occurred in the last 56 years of available rain gauge data. Some events that were not used during the calibration process (medium level peak flow events) are also presented in the graphs to indicate that the calibrated model also predicted flows for smaller storm level events within reasonable ranges. Examples of the GAC results for Rich Street and Moler Street CSO Regulators are presented in Figures 25.9 and 25.10. 


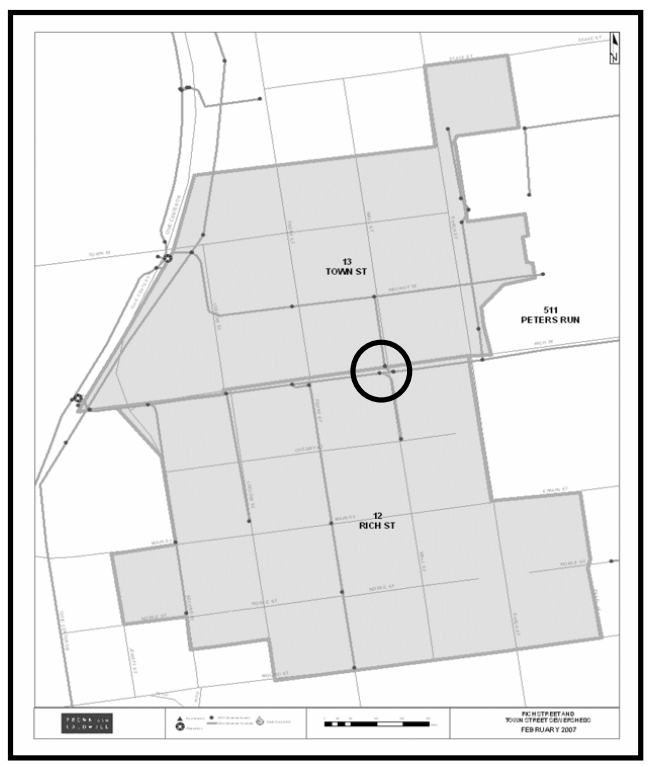

Figure 25.8 Relief connection between Town Street and Rich Street CSO Regulator Basins.

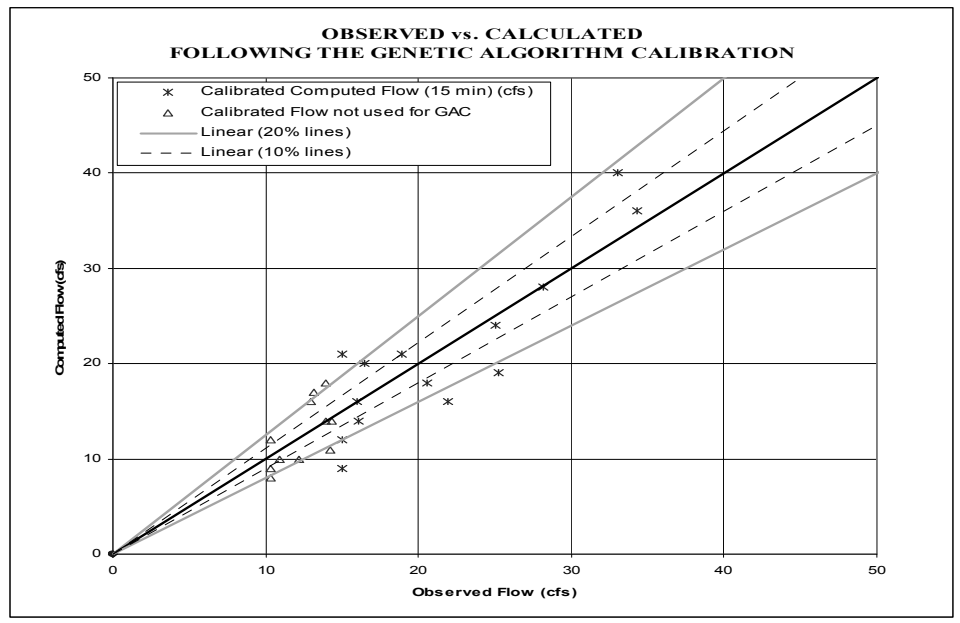

Figure 25.9 Observed vs. computed model results Rich Street CSO Regulator. 


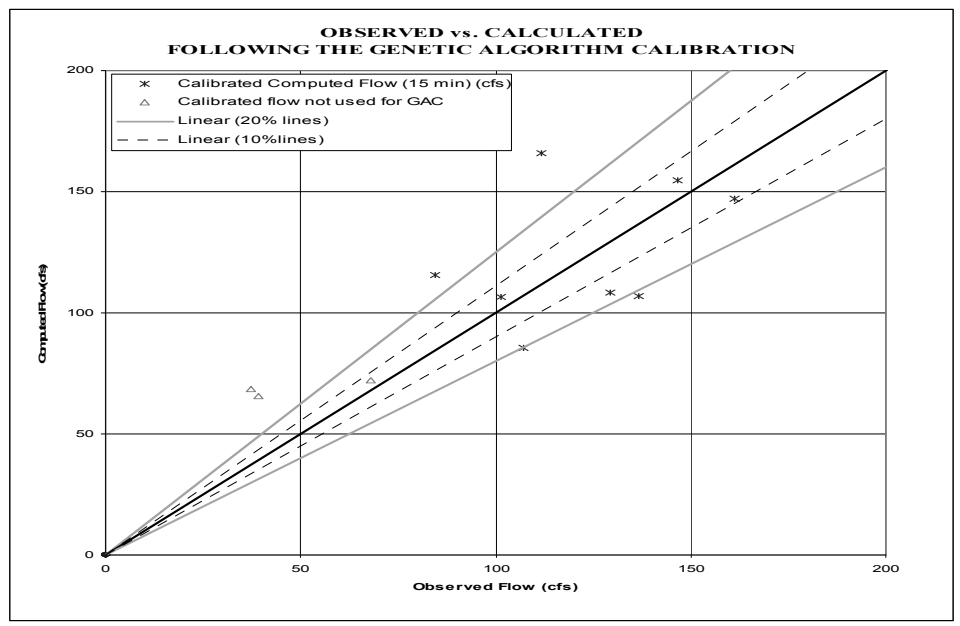

Figure 25.10 Observed vs. computed model results Moler Street CSO regulator.

Table 25.4 lists the original and final parameters for each CSO regulator basin. The level of uncertainty for each parameter varied for each basin and was not uniform throughout the evaluation process; therefore, they are not presented within this table.

\subsection{Generating Long Term Hydrograph}

The calibrated models were used to generate a long term flow response from the combined basins. This was accomplished by obtaining 56-years of rain gauge data from the Port Columbus International Airport. The same rainfall data was used for all combined basins (unlike the rainfall data derived for the GAC process where local rain gauges were used to estimate rain distribution over each basin). We used the Port Columbus International Airport rain data because the rain gauges located in downtown Columbus ranged from $8 \mathrm{y}$ to $13 \mathrm{y}$ of recorded data and needed much effort to scrub the data. 


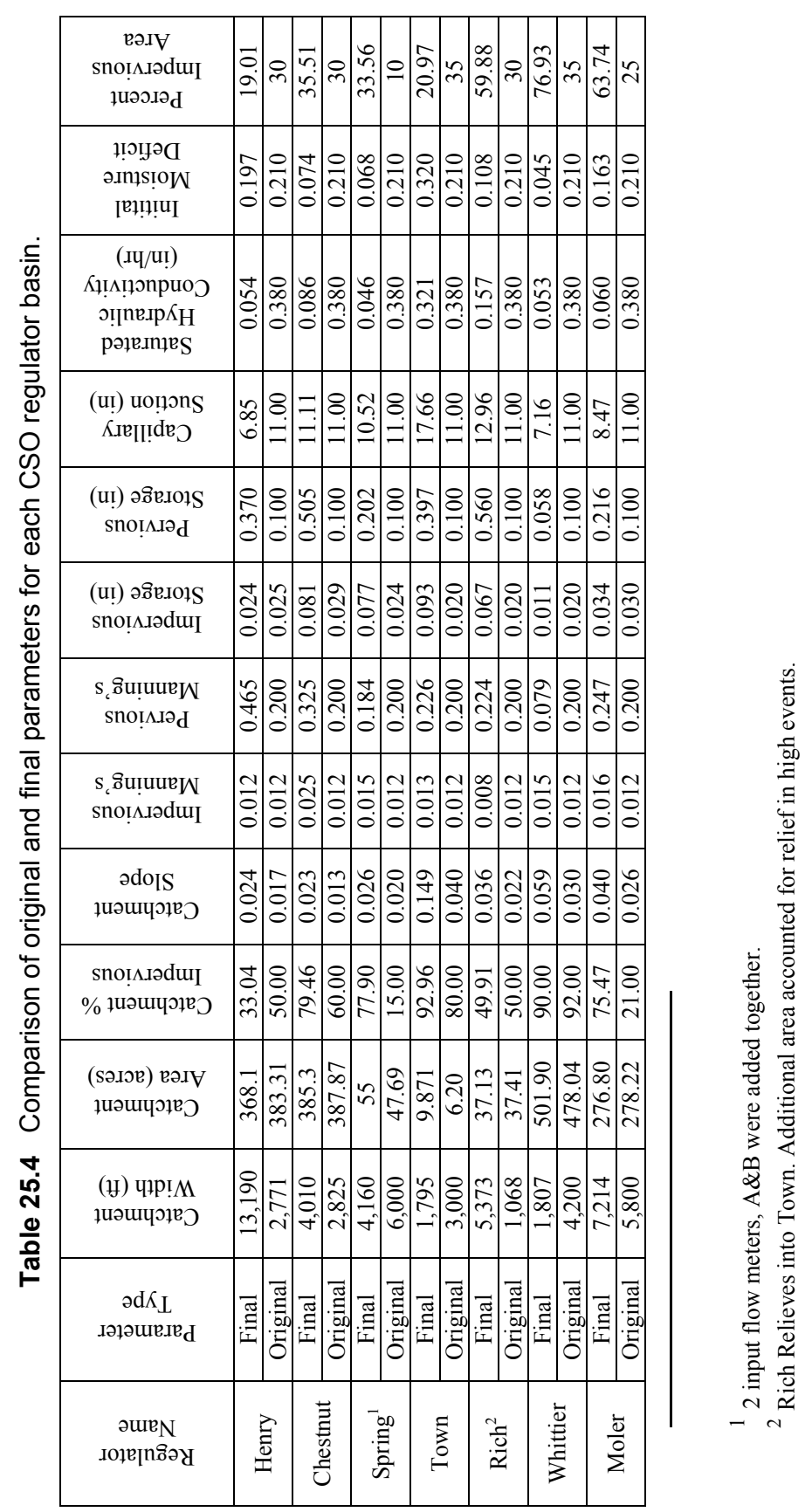




\subsection{Generating 2, 5, and 10 y Peak Flows}

\subsubsection{Plotting Position Probability Formula}

A peak flow recurrence curve was generated for each basin using the peak flows from the long term hydrograph. The first step was to obtain the highest 56 peak flows from the distinct storm events. If multiple peaks took place during one storm event, only the highest peak was used. The peak flows were then ranked from highest to lowest. Once the flows were ranked, the Plotting Position Probability Formula by Cunnane (Richard McCuen 2002) was applied to determine the return frequency corresponding to each. The Plotting Position Probability Formula by Cunnane is shown below. Examples of the ranking of the highest events for Rich Street and Moler Street CSO regulators are shown in Tables 25.4 and 25.5.

$$
\mathrm{P}_{i}=\frac{i-0.4}{n+0.2}
$$

where:

$$
\begin{aligned}
i & =\text { rank of the event, and } \\
n & =\text { sample size }
\end{aligned}
$$

The peak flow vs. the return frequency was graphed in order to develop a statistical relationship to predict the 2-, 5- and 10-y peak flows. Figures 25.11 and 25.12 illustrate the Plotting Position formula results for Rich Street and Moler Street CSO Regulator basins as examples. Because only 56 years of rain gauge data was used, the prediction accuracy of the peak flow beyond the 10-y recurrence level becomes questionable. For the sake of simplicity, a logarithmic regression curve was fitted to each dataset in order to calculate the 2-, 5-, and 10-y peak flow recurrence values specific to each basin. A better approach would be to identify an appropriate best-fit probability distribution for the data and then utilize it to determine the peak flow recurrence values. Due to time and budget limitations, we concluded that the simple regression curves give reasonable accuracy to define the needed peak flow recurrence values. 
Table 25.4 Highest peak flows for Rich Street CSO Regulator utilizing 56 years of rain gauge data.

\begin{tabular}{cccc}
\hline RANK & DATE & PEAK FLOW (cfs) & $\mathrm{P}_{\text {cunnane }}$ \\
\hline 1 & 23-Jul-02 & 102.99 & 93.7 \\
2 & 13-Jul-92 & 98.11 & 35.1 \\
3 & 10-Jun-86 & 79.87 & 21.6 \\
4 & 19-Jul-69 & 70.24 & 15.6 \\
5 & 5-Aug-95 & 64.09 & 12.2 \\
6 & 30-Aug-73 & 60.16 & 10.0 \\
7 & 13-Jun-03 & 58.78 & 8.5 \\
8 & 14-Jun-90 & 58.03 & 7.4 \\
9 & 8-Jul-52 & 57.45 & 6.5 \\
10 & 10-Jun-79 & 57.13 & 5.9 \\
\hline
\end{tabular}

Table 25.5 Highest Peak Flows for Moler Street CSO Regulator utilizing 56 years of rain gauge data.

\begin{tabular}{rrcr}
\hline RANK & DATE & PEAK FLOW (cfs) & $P_{\text {cunnane }}$ \\
\hline 1 & 13-Jul-92 & 909 & 93.7 \\
2 & $23-J u l-02$ & 869 & 35.1 \\
3 & $10-J u n-86$ & 684 & 21.6 \\
4 & $19-J u l-69$ & 602 & 15.6 \\
5 & 5 -Aug-95 & 547 & 12.2 \\
6 & 30 -Aug-73 & 532 & 10.0 \\
7 & $14-J u n-90$ & 521 & 8.5 \\
8 & 2-Aug-64 & 511 & 7.4 \\
9 & 8-Jul-52 & 510 & 6.5 \\
10 & 13-Jun-03 & 509 & 5.9 \\
\hline
\end{tabular}




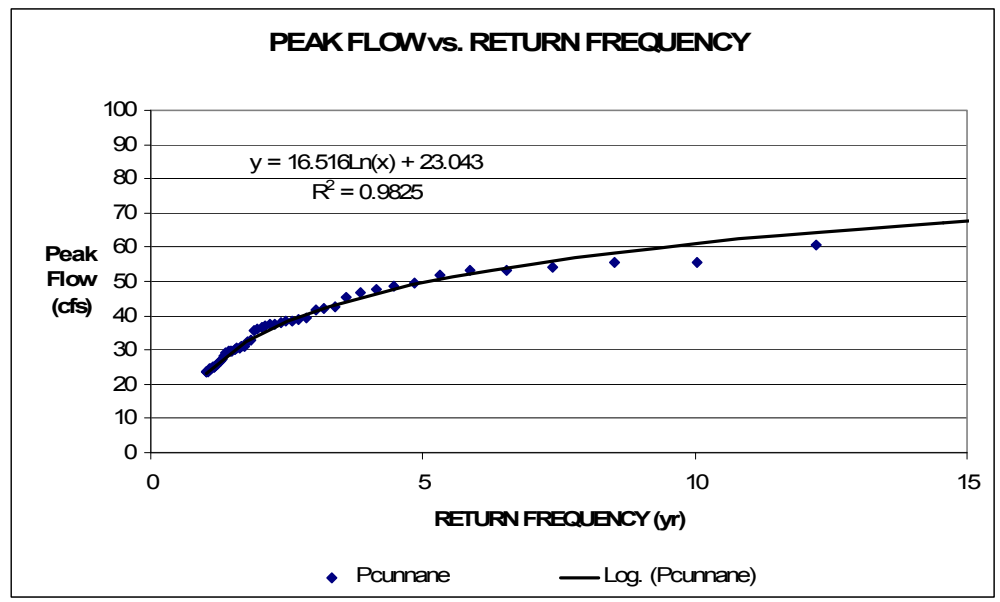

Figure 25.11 Return Frequency Curve for Rich Street CSO Regulator

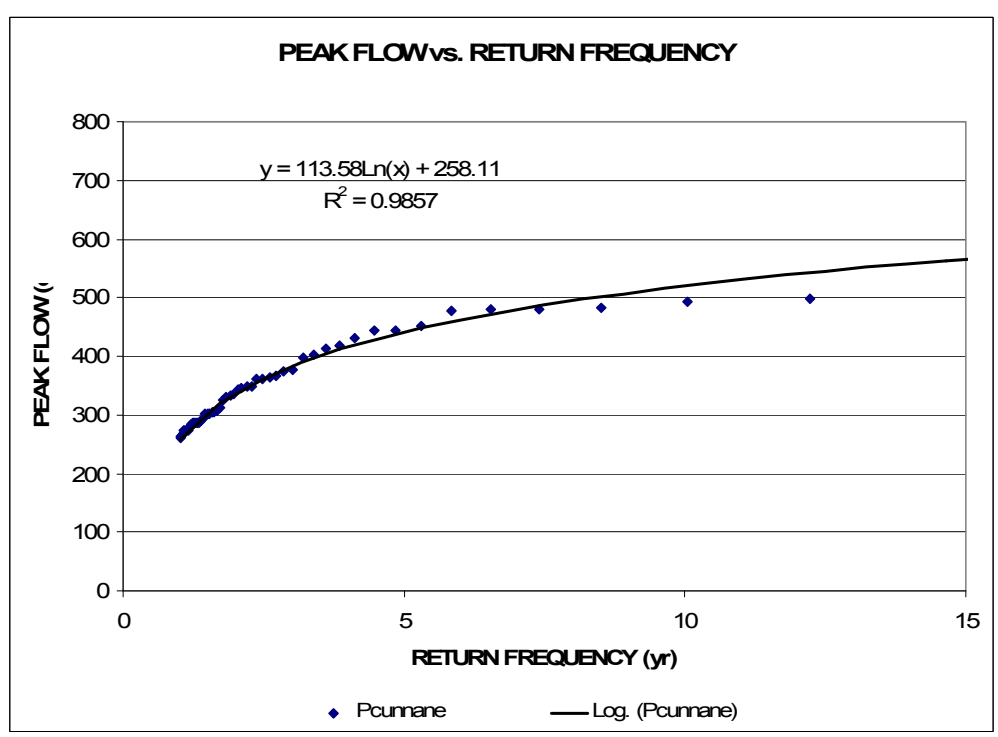

Figure 25.12 Return Frequency Curve for Moler Street CSO Regulator 


\subsubsection{Peaking Factor}

Because the only hourly rain gauge data from Port Columbus International Airport was available for the long term flow generation, the estimated peak flows are likely to be smaller than those corresponding to a 15 -min. rainfall interval due to rainfall aggregation effects. The hydraulic model was calibrated to a 15 -min. rainfall interval. In order to provide more accurate peak flow estimates for the 2-, 5- and 10-y recurrence intervals using the 1h. rainfall data, a 'peaking factor' was developed to transform the peak flows computed using the 1-h. rainfall interval to those associated with a 15minute rainfall interval. This 'peaking factor' method utilized herein is only a simplified approach to obtain a correction factor to account for the differences in the rainfall interval. A more rigorous approach would be to recalibrate the model to the $1-\mathrm{h}$. rainfall data. The new hydrology parameters would give better accurate response to the $1-\mathrm{h}$. rainfall data and then utilize the long-term rainfall data from Port Columbus International Airport to generate the peak flow estimates.

Our simplified procedure involved aggregating the available downtown 15-min. rain gauge data into $1-\mathrm{h}$. data. The previously calibrated models were then re-run to generate the peak flows using 1-h. rainfall data. Results from the 15-min. rainfall time step model were then compared to the results from the 1-h. rainfall time step model to determine the peaking factor. As expected, peak flows from the 15 -min. original rainfall data were larger than the peak flows generated from the consolidated 1-h. rainfall data. To simplify the approach, we averaged the difference resulting from evaluating the highest 10 peak flow events. This peaking factor was then applied to the 2-, 5- and 10-y peak flows calculated by the plotting position formula. As examples, Figures 25.13 and Table 25.6 give the peaking factor and corresponding peak flows for Rich Street CSO Regulator, and Figure 25.14 and Table 25.7 for Moler Street CSO Regulator.

Table 25.6 Peak flow recurrence Rich Street CSO Regulator.

\begin{tabular}{ccc}
\hline $\begin{array}{c}\text { Return Frequency } \\
\text { (yrs) }\end{array}$ & $\begin{array}{c}\text { Peak Flow } \\
\text { (cfs) }\end{array}$ & $\begin{array}{c}\text { With Peaking Factor } \\
\text { (cfs) }\end{array}$ \\
\hline 2 & 34 & 44 \\
5 & 50 & 60 \\
10 & 61 & 71 \\
\hline
\end{tabular}




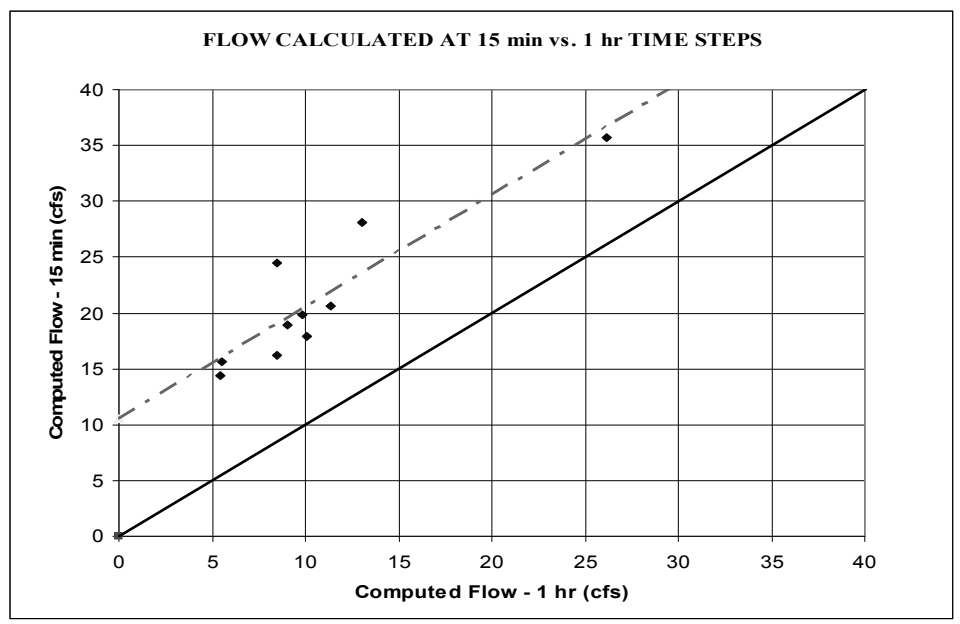

Figure 25.13 Peaking Factor to correct for 1-h. rain records from Columbus International Airport at Rich Street CSO Regulator.

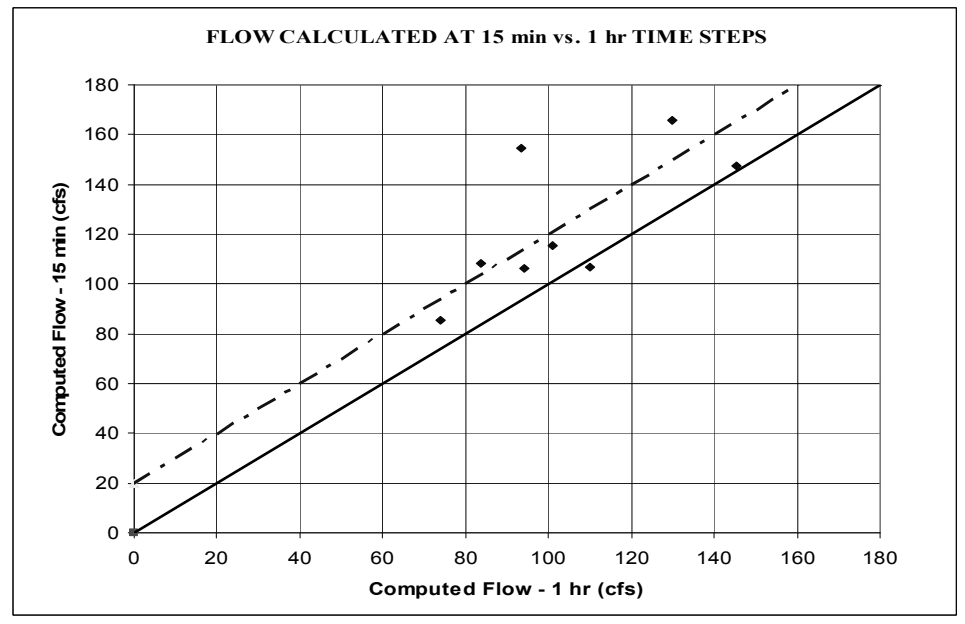

Figure 25.14 Peaking Factor to correct for 1-h. rain records from Columbus International Airport at Moler Street CSO Regulator 
Table 25.7 Peak Flow Recurrence Moler Street CSO Regulator

\begin{tabular}{ccc}
\hline $\begin{array}{c}\text { Return Frequency } \\
(\mathrm{yrs})\end{array}$ & $\begin{array}{c}\text { Peak Flow } \\
(\mathrm{cfs})\end{array}$ & $\begin{array}{c}\text { With Peaking factor } \\
(\mathrm{cfs})\end{array}$ \\
\hline 2 & 337 & 357 \\
5 & 441 & 461 \\
10 & 520 & 540 \\
\hline
\end{tabular}

\subsection{Conclusions}

The GAC tool was the best available option for this project. It provided an efficient and time-effective way to calibrate each basin model to multiple high flow events simultaneously while utilizing limited flow meter data. In this project, only the runoff module was calibrated. Possible effect of routing the flows in the combined system was assumed minimal since the combined system had enough capacity for high events and short pipes distances. It is expected that attenuation effect will be minimal.

It is of utmost importance to critically evaluate the rain gauge records and flow meters response before introducing the GAC process. Incorrect data can mislead the calibration and promote unrealistic 'calibrated' parameters. The GAC process is purely a statistical approach based and the user needs to enforce limitations during the calibration process to ensure sound hydraulic parameters. In cases where the calibration parameters extend beyond acceptable limits, further investigation is warranted. It is important to not blindly accept or reject parameter changes. A drastic change in a parameter may indicate missing information in the model simulation, like a relief connection or an inflow connection that has to date gone undetected.

\section{References}

City of Columbus Department of Public Utilities Division of Sewage and Drainage, Wet Weather Management Plan, 2005.

Computational Hydraulics Int. (CHI), PCSWMM 2004 Help Manual, Implementation of GAC in PCSWMM,

Gregory, John H., R.H. Simpson, Orris Bonney, and Robert A. Allton, Intercepting Sewers and Storm Stand-by Tanks at Columbus, Ohio, Professional Paper No. 1887, American Society of Civil Engineers, New York, 1933.

McCuen, Richard, Modeling Hydrologic Change: Statistical Methods, Lewis Publishers, Boca Raton, FL, 2002. 
